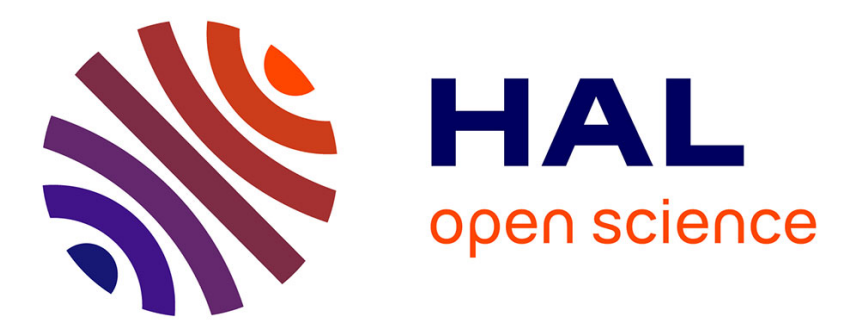

\title{
Joint inversion of EM and magnetic data for near?surface studies
}

Christophe Benech, Alain Tabbagh, Guy Desvignes

\section{To cite this version:}

Christophe Benech, Alain Tabbagh, Guy Desvignes. Joint inversion of EM and magnetic data for near?surface studies. Geophysics, 2002, 67, pp.1729 - 1739. 10.1190/1.1527074 . hal-01540344

\section{HAL Id: hal-01540344 \\ https://hal.science/hal-01540344}

Submitted on 16 Jun 2017

HAL is a multi-disciplinary open access archive for the deposit and dissemination of scientific research documents, whether they are published or not. The documents may come from teaching and research institutions in France or abroad, or from public or private research centers.
L'archive ouverte pluridisciplinaire HAL, est destinée au dépôt et à la diffusion de documents scientifiques de niveau recherche, publiés ou non, émanant des établissements d'enseignement et de recherche français ou étrangers, des laboratoires publics ou privés. 


\title{
Joint inversion of EM and magnetic data for near-surface studies
}

\author{
Christophe Benech *, Alain Tabbagh*, \\ and Guy Desvignes*
}

\section{ABSTRACT}

Magnetic and electromagnetic measurements are influenced by magnetic susceptibility and, thus, are widely used in geophysical surveys for archeology or pedology. To date, the data inversion is performed separately. A filtering process incorporating both types of data is presented here. After testing the algorithm with synthetic data, the algorithm is used in several case studies in archeological prospecting. This approach presents two advantages: establishing the presence of remanent magnetizations (viscous or thermoremanent), and achieving more refined depth analysis of the anomaly.
\end{abstract}

\section{INTRODUCTION}

Magnetic properties of soils and weathered surficial formations can be significantly different from those of the parent rock. This fact, observed 50 years ago (Leborgne, 1955; Cook and Carts, 1962), was at the origin of significant developments in both archaeological prospecting (Aitken et al., 1958; Scollar et al., 1990) and so-called environmental magnetism (Thomson and Oldfield, 1986; Verosub and Roberts, 1995).

Beside the well-known magnetic method, several electromagnetic (EM) methods can be used for measuring and mapping magnetic properties. A Slingram low-frequency apparatus (Tabbagh, 1986a) is efficient for susceptibility measurement over the first meter in depth, and it has been shown (Benech and Marmet, 1999) that this type of apparatus has a better depth of investigation and a more precise susceptibility determination than coincident or concentric loop devices.

Many studies have considered the benefits and limitations of magnetic and EM techniques in geophysical surveys (e.g., Howell, 1968; Tite and Mullins, 1969; Tabbagh, 1974, 1984; Tabbagh et al., 1988; Desvignes and Tabbagh, 1995). For example, compared to the magnetic method, the EM Slingram method allows a better reconstruction of the geometry of the features revealed by a survey, brings direct quantitative information about the apparent magnetic susceptibility, and can also detect lenslike features, but it is only sensitive to induced magnetization. The magnetic method allows a greater depth of investigation than the EM method. Nevertheless, it is not possible to distinguish between the different types of magnetization with magnetic data; these data can only be interpreted in terms of lateral variations of magnetization. Practically, the extent of disturbance generated by the presence of ferrous objects in the soil is greater for magnetic than for EM measurements.

Our aim in the present work is to enhance the quality of interpretation by simultaneous use of EM and magnetic data, and to exploit their complementarity. An equivalent approach has already been achieved for borehole data using the 1-D approximation (Desvignes et al., 1992). In this paper (as we did in Desvignes. et al., 1992), we use linear filtering to separate the induced magnetisation from the remanent effects. Because the geometrical factor that governs the magnitude of the response of a given point underground is different in the magnetic method and in each type of EM instrument, observed variations in the induced magnetization reflect the geometry of the source.

\section{FILTERING PROCESS}

In the magnetic method, if one neglects the demagnetizing field and considers only the induced magnetization, the magnetic response can be expressed as a convolution product:

$$
\Delta T(x, y)=\int_{0}^{\infty} \chi\left(x, y, z_{0}\right) \otimes R_{m}\left(x, y, z_{0}\right) d z_{0} ;
$$

where $\Delta T(x, y)$ is the anomalous magnetic field, $\chi\left(x, y, z_{0}\right)$ is the 3-D distribution of anomalous susceptibility, and $R_{m}\left(x, y, z_{0}\right)$ is the magnetic impulse response i.e., the response of a dipole located at $\mathrm{z}_{0}$ depth and aligned with the incident field. This approximation is generally acceptable for the study of a subsurface structure where the demagnetizing field is

Manuscript received by the Editor September 12, 2000; revised manuscript received November 6, 2001.

*Université Pierre et Marie Curie, Department de Geophysique Appliqueé, Case 105, 4, place Jussieu, 75252 Paris Cedex 05, France. E-mail: benech@ccr.jussieu.fr.

(C) 2002 Society of Exploration Geophysicists. All rights reserved. 
negligible; that is, with the exception of very magnetic rocks (e.g., basic or ultrabasic) (Telford et al., 1990).

In the EM domain, if the demagnetizing field is negligible and if the crosscoupling between electrical and magnetic sources is also negligible (Tabbagh, 1985), the response of the apparatus, in terms of the apparent magnetic susceptibility, can be expressed by another convolution product:

$$
\chi_{a}(x, y)=\int_{0}^{\infty} \chi\left(x, y, z_{0}\right) \otimes R_{e m}\left(x, y, z_{0}\right) d z_{0},
$$

where $R_{e m}\left(x, y, z_{0}\right)$ is the EM impulse response. In the spectral domain, the convolution products of equations (1) and (2) are direct products:

$$
\begin{aligned}
\Delta \hat{T}(u, v) & =\int_{0}^{\infty} \hat{\chi}\left(u, v, z_{0}\right) \hat{R}_{m}\left(u, v, z_{0}\right) d z_{0}, \\
\hat{\chi}_{a}(u, v) & =\int_{0}^{\infty} \hat{\chi}\left(u, v, z_{0}\right) \hat{R}_{e m}\left(u, v, z_{0}\right) d z_{0},
\end{aligned}
$$

where $u$ and $v$ are the spatial frequencies corresponding to the $x$ and $y$ directions, respectively, and $\hat{F}(u, v)$ is the Fourier transform of $F(x, y)$. For an induced magnetization, the impulse magnetic response is simple, and its Fourier transform is known:

$$
\begin{aligned}
\hat{R}_{m}(u, v, z)= & 4 \pi^{2} \frac{e^{-2 \pi z \sqrt{u^{2}+v^{2}}}}{\sqrt{u^{2}+v^{2}}}(i u \cos D \cos I \\
& \left.+i v \sin D \cos I+\sqrt{u^{2}+v^{2}} \sin I\right)^{2},
\end{aligned}
$$

where $I$ is the inclination of the earth magnetic field, and $D$ is the declination. The impulse EM response has a complex expression that depends on the characteristics of the apparatus and on electrical and magnetic properties of the surrounding soil. Knowing the transmitter magnitude and orientation, one calculates the transmitted field at the dipole location; each component generated by the induced magnetic dipole is then calculated at the location of the receiver and projected on its axis. The analytical expressions, which correspond to Hankel transforms, have been already published (Tabbagh, 1985). This calculation is performed at each point of the measurement grid. Then, the 2-D numerical Fourier transform is calculated.

By taking the ratio of equations (3) and (4), we obtain a linear relation between the Fourier transform of an induced magnetization magnetic anomaly and the Fourier transform of an apparent susceptibility anomaly:

$$
\frac{\Delta \hat{T}(u, v)}{\hat{\chi}_{a}(u, v)}=\frac{\int_{0}^{\infty} \hat{\chi}\left(u, v, z_{0}\right) \hat{R}_{m}\left(u, v, z_{0}\right) d z_{0}}{\int_{0}^{\infty} \hat{\chi}\left(u, v, z_{0}\right) \hat{R}_{e m}\left(u, v, z_{0}\right) d z_{0}} .
$$

Equation (6) can be simplified in two cases. If $\hat{\chi}\left(u, v, z_{0}\right)$ is assumed to be independent of $\mathrm{z}_{0}$, then

$$
\frac{\Delta \hat{T}(u, v)}{\hat{\chi}_{a}(u, v)}=\frac{\int_{0}^{\infty} \hat{R}_{m}\left(u, v, z_{0}\right) d z_{0}}{\int_{0}^{\infty} \hat{R}_{e m}\left(u, v, z_{0}\right) d z_{0}} .
$$

This equation will be used for the synthetic and experimental test data presented below.

If $\hat{\chi}\left(u, v, z_{0}\right)=\chi_{1}(u, v) \delta\left(z_{0}-z_{1}\right)$, when all the susceptibility contrast is localized in a thin layer at $z_{2}$, then

$$
\frac{\Delta \hat{T}(u, v)}{\hat{\chi}_{0}(u, v)}=\frac{\hat{R}_{m}\left(u, v, z_{2}\right)}{\hat{R}_{e m}\left(u, v, z_{2}\right)} .
$$

Several tests on synthetic data (see the following section) have established that either equation (7) or equation (8), if the $z_{2}$ value is correctly chosen, can give sufficiently accurate results. Both can be used as a filter function allowing us to deduce the magnetic anomaly generated by induced magnetization from the EM anomaly.

$R_{m}$ and $R_{e m}$ can be calculated using two methods: use one dipole located at a mean depth representation of the anomalous feature, or use a vertical series of dipoles extending over the thickness of the feature. The difference in investigation depth between magnetic and EM methods must also be taken into account for the choice of the dipole(s) depth because some deep features may influence the magnetic response but not the EM one (this situation will generate a difference between the measured magnetic anomaly and the magnetic anomaly obtained by filtering the EM data). The choice of the dipole(s) depth will require successive trials but, in turn, the agreement between the original magnetic anomaly and the magnetic anomaly obtained by filtering EM data can be used as a criterion for estimating the depth of a source.

\section{TEST ON SYNTHETIC DATA}

\section{"L"-shaped feature}

We first consider a "L"-shaped feature (Figure 1) and an induced magnetization only. Our interest in this geometry is

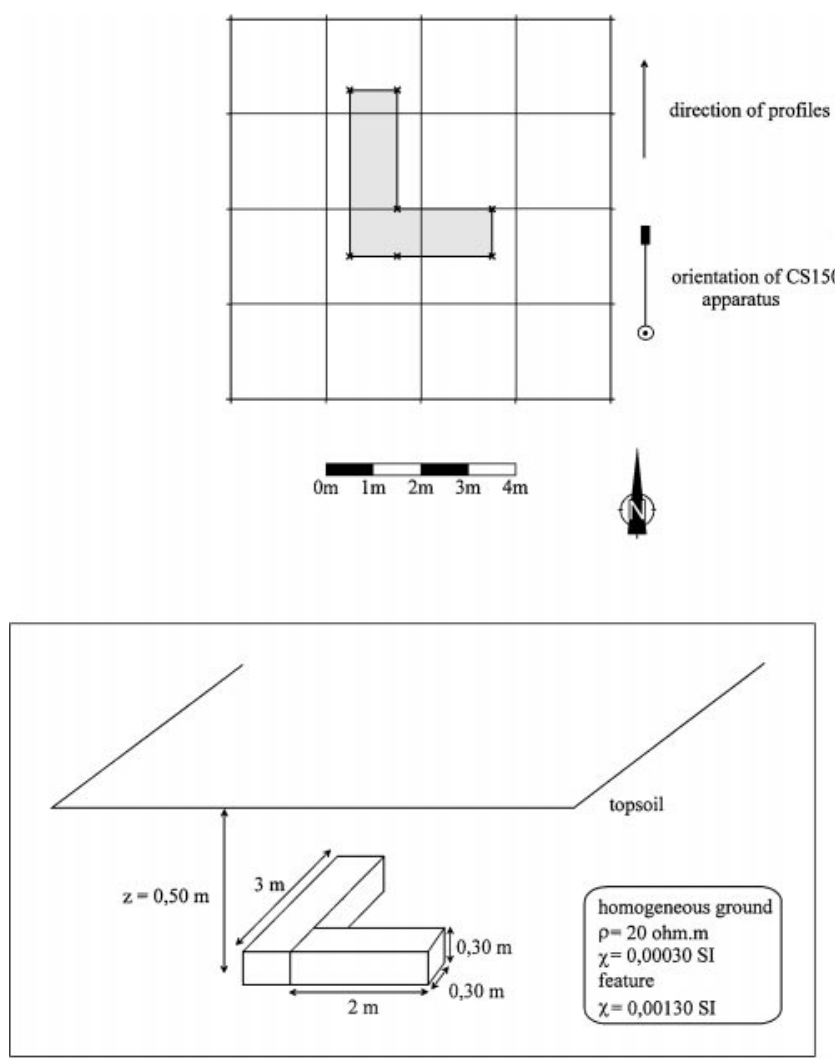

FIG. 1. Geometry and properties of a "L"-shaped test model. 
to present two different horizontal branch orientations which take into account the absence of lateral isotropy of both the primary fields and the measured components.

Figures $2 \mathrm{a}$ and $2 \mathrm{~b}$ show the results obtained, respectively, for the CS150 apparatus (perpendicular-to-each-other coil configuration, $4.4-$ and $10-\mathrm{kHz}$ frequencies, $1.50-\mathrm{m}$ separation between the coils, coils at $0.22-\mathrm{m}$ altitude) (Beaussillon et al., 1996) and for a total field magnetometer with a sensor at $0.30 \mathrm{~m}$ above the ground. In the CS150 results, the anomaly maximum obtained for the branch perpendicular to the profiles is slightly offset, the perpendicular configuration of the coils delivering a weakly assymmetric response (Tabbagh, 1986b).

The EM data were filtered with a function $R_{e m}$ calculated using one dipole at the mean depth of $0.50 \mathrm{~m}$ (Figure 2c) and also using a series of three dipoles located at $0.45,0.55$, and $0.65 \mathrm{~m}$ depths (Figure 2d), this latter distribution corresponding to the entire thickness of the feature. In both cases, the shape and location of the magnetic anomaly obtained by filtering the EM data is very similar to the one obtained with synthetic magnetic data. The data obtained by using the threedipole filter function show only minor differences with the synthetic magnetic data (Table 1). In the case of one dipole, the minimum and the maximum are a little overestimated, and the standard deviation of the data is a little more significant $(\sim 0.1 \mathrm{nT})$.

Table 1. Characteristics of magnetic and $E M$ data for the " $L$ "shaped feature with the CS150 apparatus.

\begin{tabular}{lccc}
\hline & $\begin{array}{c}\text { Minimum } \\
(\mathrm{nT})\end{array}$ & $\begin{array}{c}\text { Maximum } \\
(\mathrm{nT})\end{array}$ & $\begin{array}{c}\text { Standard } \\
\text { deviation }\end{array}$ \\
\hline Magnetic data & -1.18 & 3.32 & 0.69 \\
Filtered EM data (1 dipole) & -1.11 & 3.59 & 0.75 \\
Filtered EM data (3 dipoles) & -1.17 & 3.31 & 0.69 \\
\hline
\end{tabular}

a)

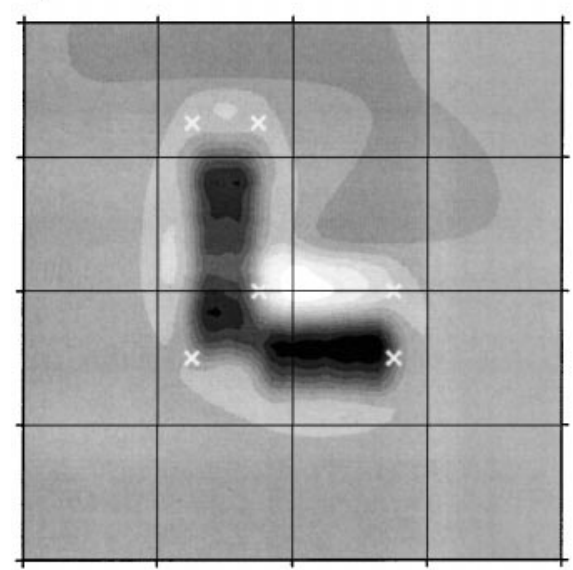

units : E-5 SI b)

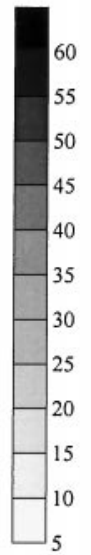

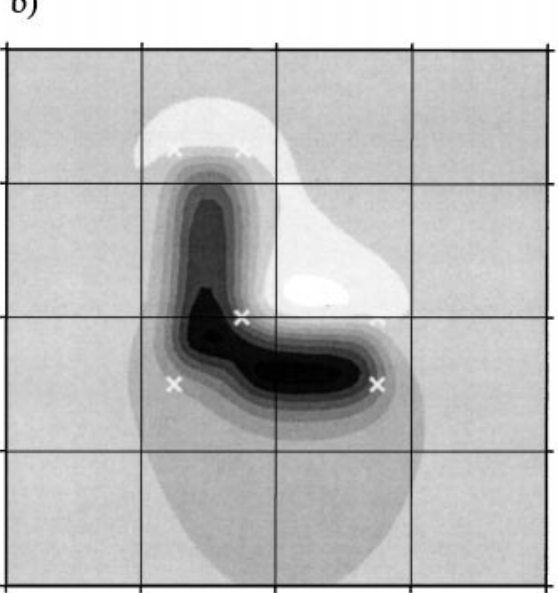

units : nT

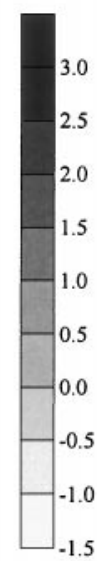

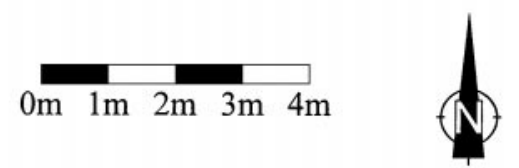

c)

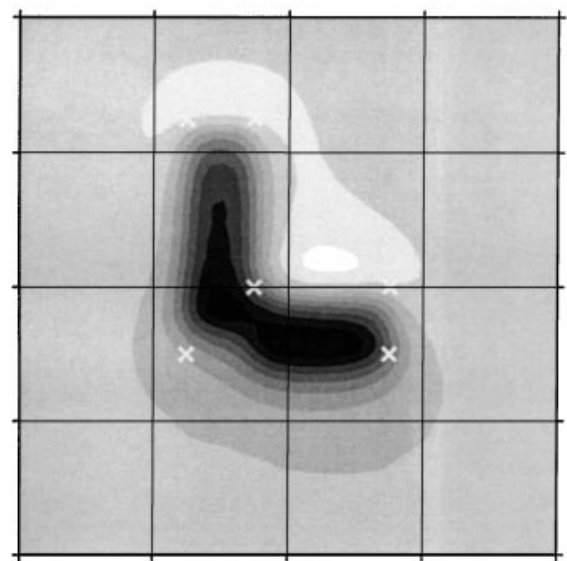

units : nT

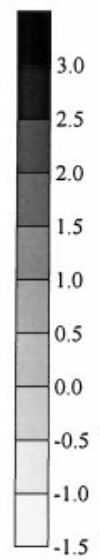

d)

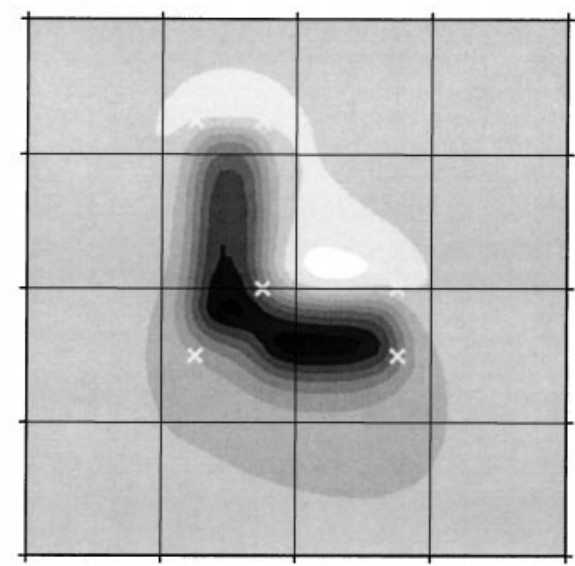

units : nT

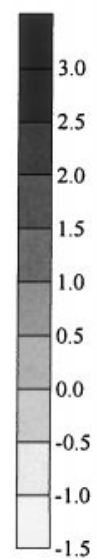

FIG. 2. Maps of the "L"-shaped feature with the CS150 apparatus (4.4 kHz): (a) EM apparent susceptibility (the original data), (b) magnetic data, (c) filtered data from one dipole, (d) filtered data from three dipoles. The $\times$ symbols indicate the limits of the "L"-shaped test feature. 
The same simulation is performed for the SH3 apparatus characteristics (parallel-to-each-other coil configuration, $1.5-\mathrm{m}$ separation, $8.04 \mathrm{kHz}$ ). As in the case of the CS150 apparatus, the configuration of the coils gives an assymmetric response, and the anomaly is slightly offset from the location of the feature. The EM data were filtered using one- and three-dipole filter functions. In this case too, the magnetic anomaly obtained by filtering the EM data correctly fits the synthetic magnetic anomaly in magnitude as well as in location (Table 2). However, the result obtained with the one-dipole filter is slightly better than with the three-dipole filter.

This first test shows that at shallow depth and for features of limited thickness, the filter calculated for only one dipole located at a mean depth gives similar results to those obtained with the three-dipole filter. Because of their different coil configurations, the CS150 and the SH3 apparatuses give different apparent susceptibility responses, but the magnetic anomalies obtained by filtering these data are very similar.

\section{Prism with a significant depth extension}

The cubic prism is presented in Figure 3 and extends between 0.50 and $2.50 \mathrm{~m}$ in depth. The two Slingram systems (the CS150 and SH3) do not sample the totality of the feature but only its upper part, the approximate depths of investigation of C150 and SH3 being, respectively, $1 \mathrm{~m}$ and $0.70 \mathrm{~m}$ for susceptibility measurements. On the contrary, magnetic measurements are affected by the entire feature.

Here, the anomaly obtained with the CS150 apparatus does not correspond exactly to the geometry of the feature (Figure 4a), because of the feature's extension in depth. By calculating an EM transfer function with a dipole located at 1-m depth, we obtained a magnetic anomaly weakly inferior (with a 0.93 magnitude ratio) to the synthetic magnetic case. For a dipole located at $0.60-\mathrm{m}$ depth, this ratio decreases to 0.74 (Table 3). Even if the difference of amplitude between filtered EM and magnetic data remains relatively limited, the difference of depth of investigation between the CS150 and the magnetic method has a clear effect (Figures $4 b$, c, and d). This difference is more important in the case of the $\mathrm{SH} 3$ apparatus (Figure 5a) because its depth of investigation is inferior to the CS150 apparatus. If the transfer function is calculated with a dipole at $0.60-\mathrm{m}$ depth, the shape of the anomaly is slightly changed, but its amplitude is four times smaller than that of the synthetic magnetic case.

The difference in depth of investigation between the magnetic method and the different EM apparatus is thus a main parameter to consider when simultaneously inverting EM and magnetic data.

Table 2. Characteristics of magnetic and EM data for the " $L$ "shaped feature with the $\mathrm{SH} 3$ apparatus.

\begin{tabular}{lccc}
\hline & $\begin{array}{c}\text { Minimum } \\
(\mathrm{nT})\end{array}$ & $\begin{array}{c}\text { Maximum } \\
(\mathrm{nT})\end{array}$ & $\begin{array}{c}\text { Standard } \\
\text { deviation }\end{array}$ \\
\hline Magnetic data & -1.18 & 3.32 & 0.69 \\
Filtered EM data (1 dipole) & -1.11 & 3.43 & 0.76 \\
Filtered EM data (3 dipôles) & -1.04 & 3.13 & 0.67 \\
\hline
\end{tabular}

HORIZONTAL SHEETLIKE FEATURE: THE PROBLEM OF THE EQUIVALENT STRATUM

The equivalent stratum problem is well known in magnetism: the magnetic response of a feature at a given depth is equivalent to the response of a thin sheetlike feature at a shallower depth (Pedersen, 1991). The reciprocal effect of this equivalence can be a problem in the interpretation of the filtered EM data if a true susceptibility variation inside the near-surface layer is interpreted as generated by a deeper feature.

Consider a thin horizontal magnetic stratum with laterally varying values of susceptibility, located at $0.10-\mathrm{m}$ depth (Figure 6). The corresponding apparent susceptibility map presents an asymmetry when considering, for example, the parallel orientation of the SH3 apparatus (Figure 7a). By filtering the EM data with a filter calculated with one dipole at $0.10-\mathrm{m}$ depth, one reconstructs the magnetic anomaly (Figure 7b).

Starting from this anomaly, if one first calculates the equivalent stratum at $0.10-\mathrm{m}$ depth, the original susceptibility distribution is recovered. This corresponds to the fact that the equivalent stratum concept applies also in EM measurements and that the inverse problem has an infinite number of solutions. A given EM apparent susceptibility anomaly can be interpreted as resulting from a thin layer located at any chosen depth; the lateral susceptibility variation inside the layer can be calculated by filtering.

Secondly, if one tries to estimate the depth of the magnetic source by using Euler's deconvolution (Hood, 1965; Thompson, 1982), one obtains a result equal to $0.32 \mathrm{~m}$ with

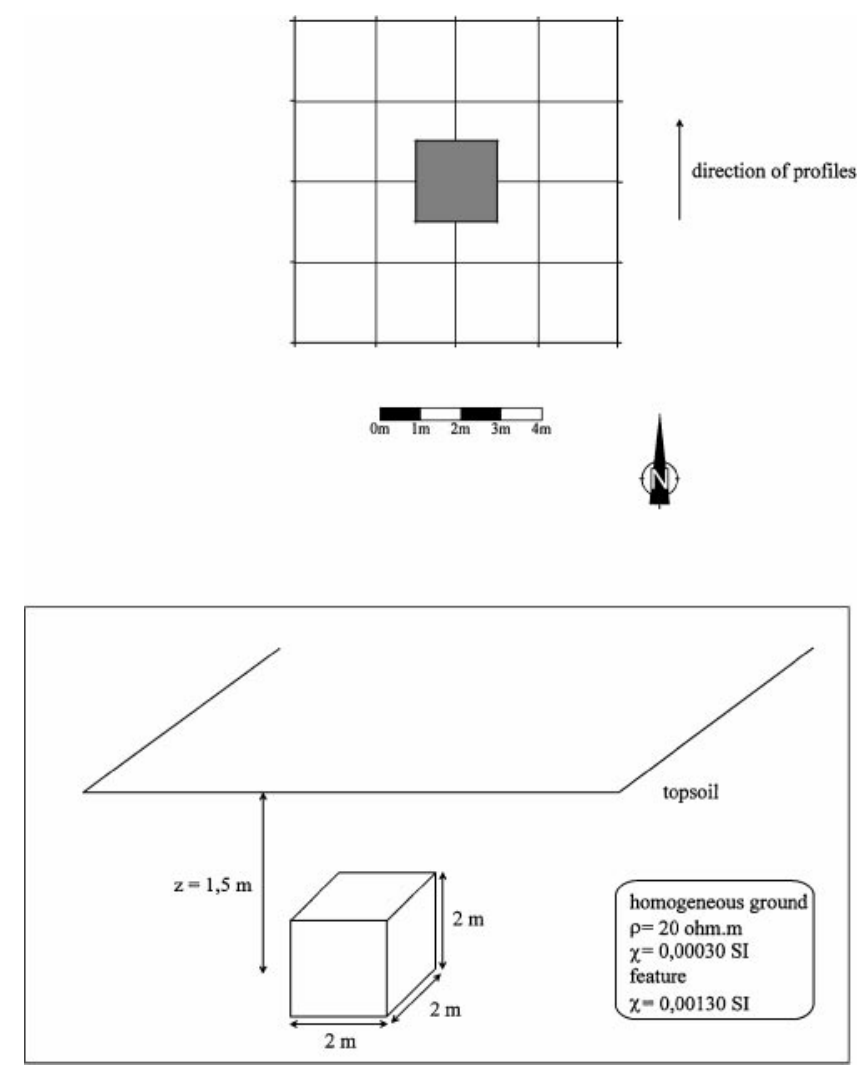

FIG. 3. Location and characteristics of prism feature. 
a structural index, $N$, equal to 2 (Desvignes et al., 1999), which is a likely value for nonelongated features. In this case, the depth of the source is overestimated. As we will see later, such a situation can be met in specific experimental cases where farmers ploughing the field may have scattered the upper parts of a magnetic feature in the soil layer.

\section{TESTS ON EXPERIMENTAL DATA}

\section{Pottery workshop of Dampierre sous Bouhy (Nièvre, France)}

This pottery workshop from the 17th century was first surveyed with the SH3 apparatus and a TDEM apparatus (Decco, Littlemore Ltd.) using a coarse survey grid $\left(5 \times 5 \mathrm{~m}^{2}\right)$ and later with both the $\mathrm{SH} 3$ apparatus and a cesium gradiometer (G858 Geometrics) using a $1 \times 1 \mathrm{~m}^{2}$ grid. To test the simultaneous inversion using linear filtering, we chose a marked anomaly (thought to be a kiln) likely having a high remanent magneti- zation. According to EM data, the apparent magnetic susceptibility of this feature is about $400 \times 10^{-5}$ SI (Figure $8 \mathrm{a}$ ). The magnetic anomaly presents a high (peak-to-peak) amplitude about $500 \mathrm{nT}$ (Figure 8b).

For this study, we proceed step by step:

1) Determine the magnetic source depth using Euler's deconvolution.

Table 3. Characteristics of magnetic and EM data for the prism with great depth extension with the CS150 apparatus.

\begin{tabular}{lccc}
\hline & $\begin{array}{c}\text { Minimum } \\
(\mathrm{nT})\end{array}$ & $\begin{array}{c}\text { Maximum } \\
(\mathrm{nT})\end{array}$ & $\begin{array}{c}\text { Standard } \\
\text { deviation }\end{array}$ \\
\hline Magnetic data & -1.31 & 7.21 & 1.47 \\
$\begin{array}{l}\text { Filtered EM data } \\
\quad(1 \text { dipole at } 1 \mathrm{~m})\end{array}$ & -1.39 & 6.53 & 1.29 \\
$\begin{array}{c}\text { Filtered EM data } \\
(1 \text { dipole at } 0.60 \mathrm{~m})\end{array}$ & -1.41 & 4.86 & 0.93 \\
\hline
\end{tabular}

a)

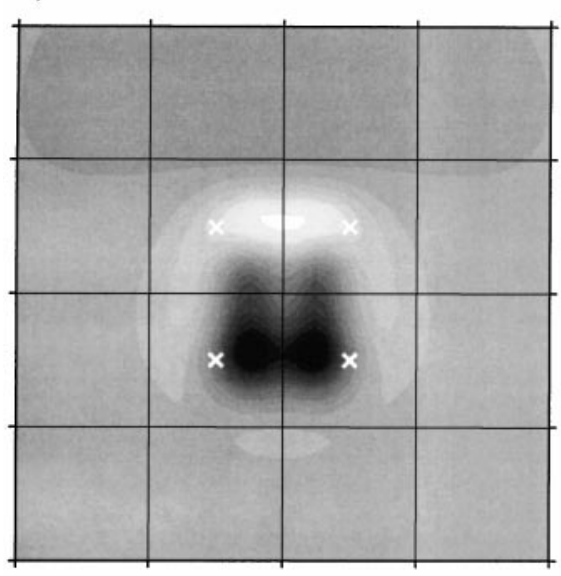

units : E-5 SI

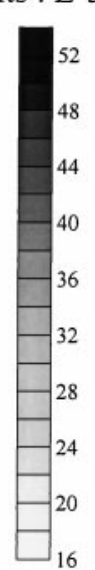

b)

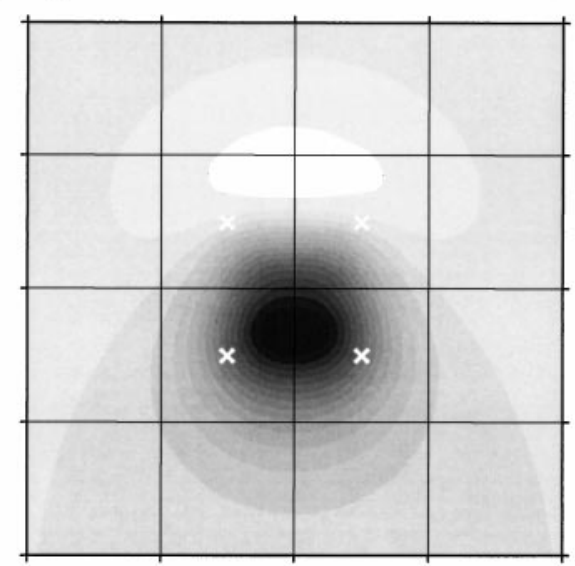

units : nT

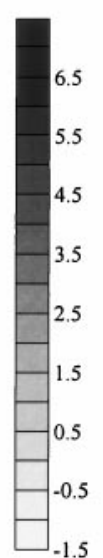

c)

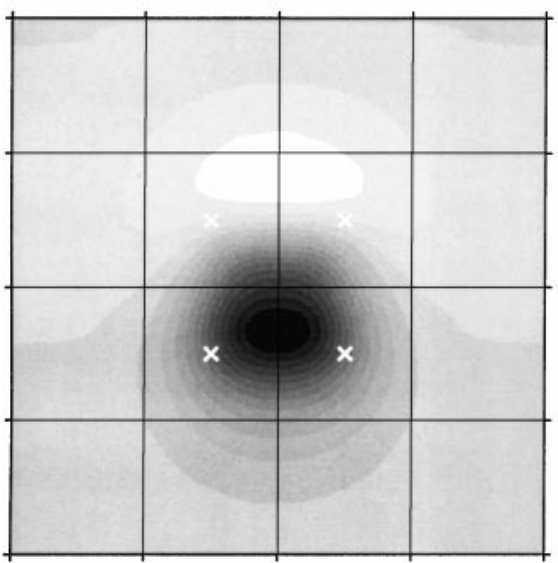

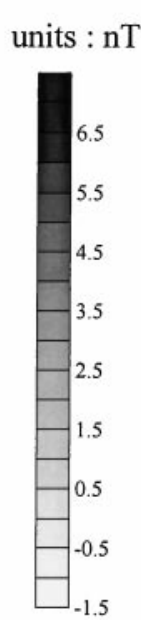

d)

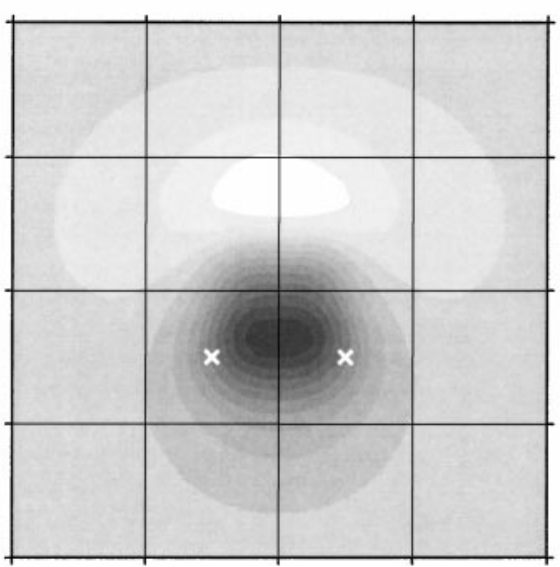

units : nT

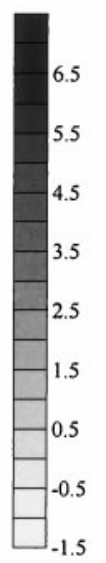

FIG. 4. Maps of a prism feature with the CS150 apparatus: (a) EM apparent susceptibility (the original data), (b) magnetic data, (c) filtered data from one dipole at 1-m depth, (d) filtered data from one dipole at 0.60-m depth. 
2) Linear filter the EM data with a dipole at this depth.

3) Verify the magnetic source depth of the magnetic anomaly obtained by filtering the EM data again using Euler's deconvolution.

We should expect to obtain the same depth in steps 1 and 3 . If it is not the case, we repeat the same steps with various structural indices for the Euler deconvolution.

4) Subtract the magnetic anomaly obtained by filtering the EM data from the measured magnetic data.

In the present case, the measured magnetic data resulted in a source depth of $0.36 \mathrm{~m}$ using a structural index of $N=1.8$. The index suggests a lenslike geometry of the magnetic part of the feature (Desvignes et al., 1999), and we obtained the same result with Euler's deconvolution of electromagnetic data filtered with one dipole at 0.36-m depth (Figure 9). The anomaly source is therefore likely located in the range of depth of investigation of the $\mathrm{SH} 3$ apparatus, and we can conclude that the differences observed between measured and filtered magnetic anomalies are due to the presence of some remanent magnetization. The part of the magnetic anomaly due to this magnetization (mapped in Figure 10) is 12.4 times higher in amplitude than that of the induced magnetization. By interpreting it as a thermoremanent magnetization, the amplitude ratio corresponds to a global Koenigsberger's ratio, $Q$, for the whole feature. The literature reports that $Q$ ratios for kiln elements are usually between 4 and 100 (Chauvin et al., 2000).

\section{Iron Age site of Verdun sur le Doubs (Saône et Loire, France)}

This site is situated on an alluvial plain downstream from the confluence of the Doubs and Saône rivers in France. Limited archeological excavations have shown pits and semipit a)

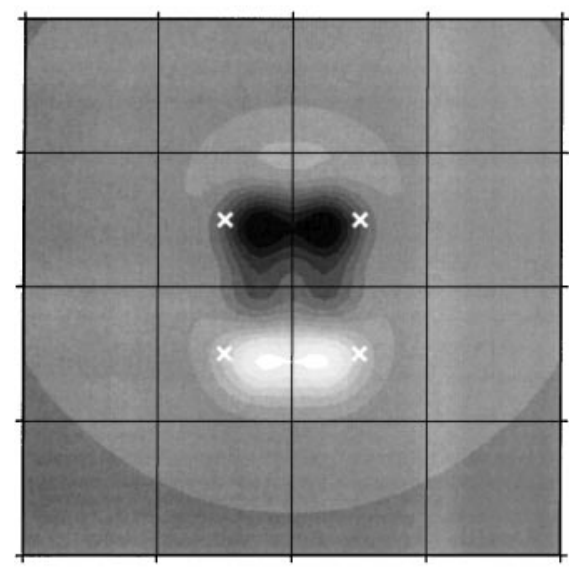

units : E-5 SI

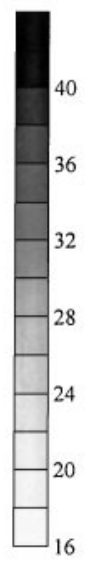

b)

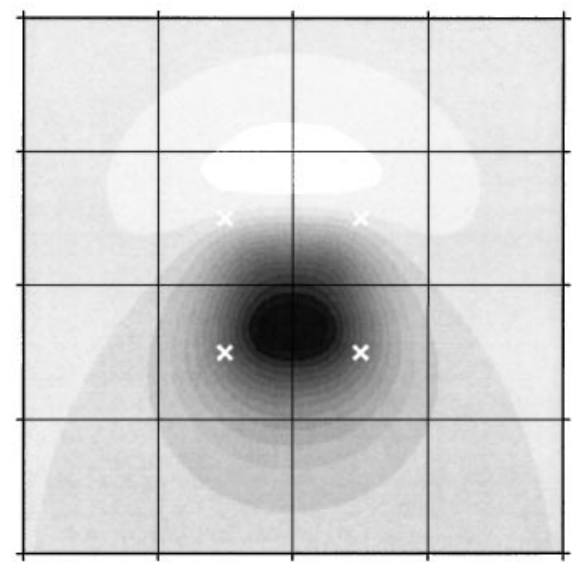

units : nT

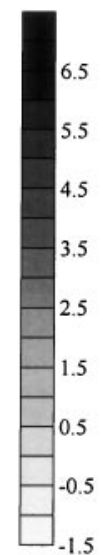

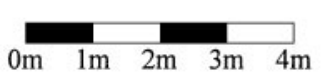

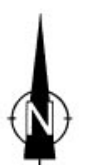

c)
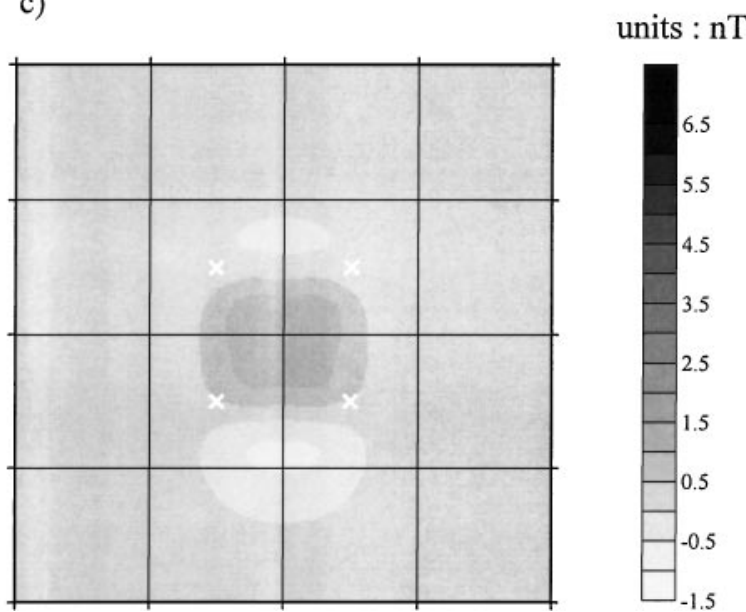

FIG. 5. Maps of a prism feature with the SH3 apparatus: (a) EM apparent susceptibility (the original data), (b) magnetic data, (c) filtered data from one dipole at $0.60-\mathrm{m}$ depth. 
habitations at about $0.50-\mathrm{m}$ depth. Two hectares were surveyed with a cesium gradiometer (G858 Geometrics). We selected a $20 \times 20 \mathrm{~m}^{2}$ area where significant magnetic anomalies were found previously (Figure 11a).

This survey was the first archeological application of the CS150 Slingram apparatus built at the Centre de Recherches Géophysiques of Garchy, France (Beaussillon et al., 1996). The map obtained with the CS150 apparatus (Figure 11b) corresponds well with the magnetic map. An archeological excavation performed on three main anomalies identified Iron Age pits (Figure 12). The infills of pits 1,2, and 3 are $1.50 \mathrm{~m}$, $0.50 \mathrm{~m}$, and $2.20 \mathrm{~m}$ thick (two of them thus exceed the CS150 depth of investigation). This type of feature have probably no thermoremanent magnetization, but the presence of a viscous magnetization is likely.

Euler's deconvolution on magnetic data delivers a depth of $0.25 \mathrm{~m}$ for $N=1$ and $0.60 \mathrm{~m}$ for $\mathrm{N}=2$. Even if these features are thick, the magnetic sources are located in the upper part of the feature at a depth shallower than the CS150 depth of investigation. The differences observed between magnetic measurements and magnetic data obtained by filtering the EM data thus will indicate in the presence of another type of magnetization.

The best agreement in source-depth determination is obtained for $\mathrm{N}=1.1$, for which we get for both magnetic anomalies a depth of $0.32 \mathrm{~m}$. This result was confirmed by excavation, which showed that the major part of the archeological artefacts occurs around this depth. Measured magnetic anomalies present amplitudes 1.76 times higher than those obtained by
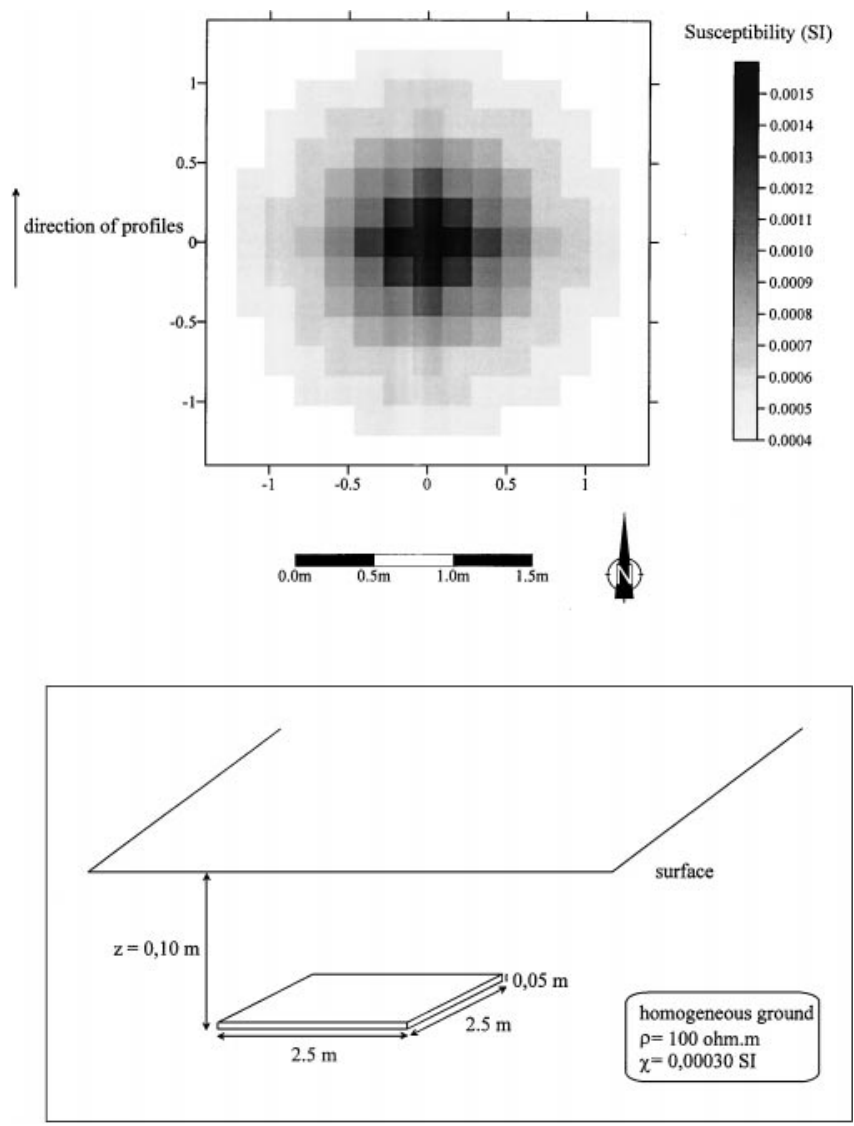

FIG. 6. Location and characteristics of sheet-shaped feature. filtering the EM data (Table 4). This difference can be interpreted by the presence of a viscous magnetization of the feature which has remained in place for 2000 years. Using the theory of dispersed single-domain grains (Néel, 1949; Dabas and Skinner, 1993), it is possible to calculate the time domain coefficient of viscosity, $s$, using the formula.

$$
\chi(t)=\chi_{a c}\left[1+s \ln \left(t \frac{\omega}{\pi}\right)\right],
$$

where $\chi_{a c}$ is the susceptibility at $\omega$ angular frequency. With an experimental ratio $\left(\chi(t) / \chi_{a c}\right)$ equal to 1.76 for $t=2000$ years, one deduces $s=0.022$.

The corresponding quadrature to in-phase susceptibility ratio would be: $\chi_{q} / \chi_{p}=(\pi / 2) s=3.5 \%$. This ratio is in good

a)
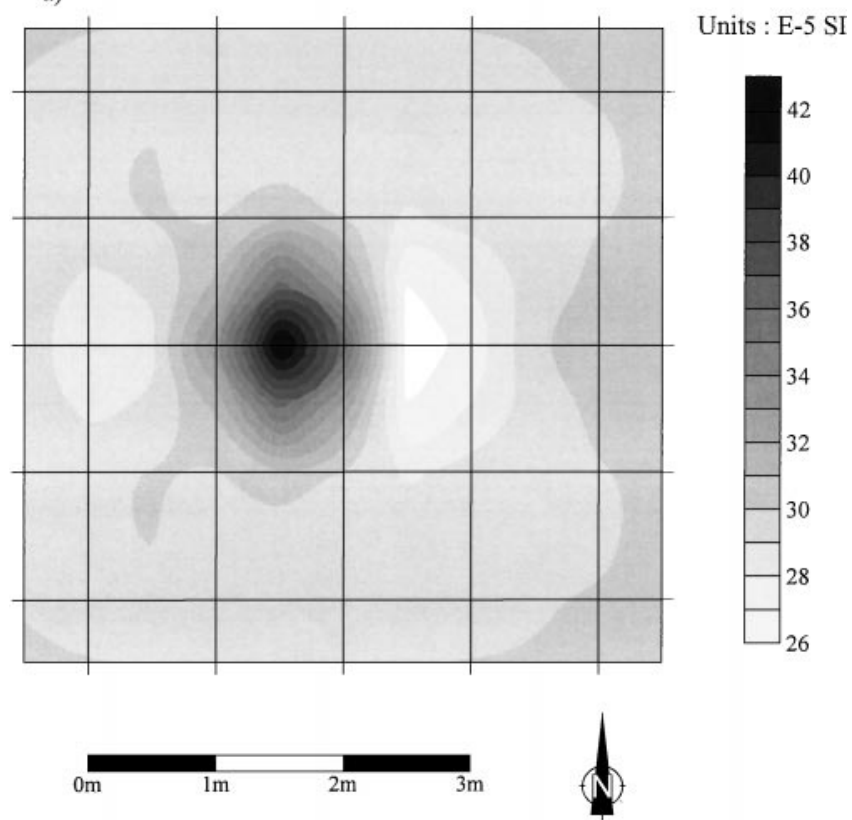

b)

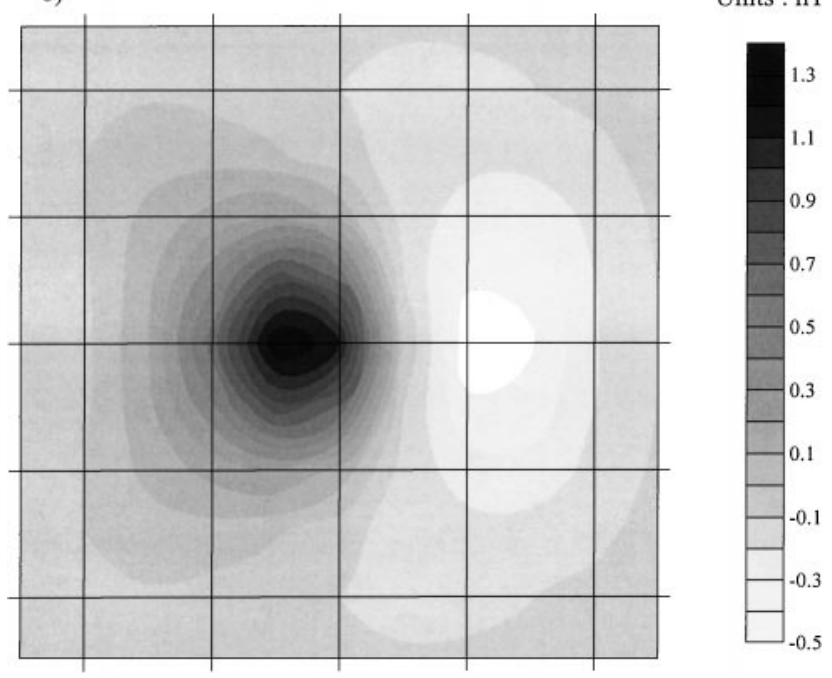

FIG. 7. Maps of sheet-shaped feature with the $\mathrm{SH} 3$ apparatus: (a) EM apparent susceptibility (the original data), (b) filtered data from one dipole at $0.20-\mathrm{m}$ depth. 
agreement with the values already published (Mullins, 1974; Dabas and Skinner, 1993). The presence of a viscous magnetization is crucial for the archeological interpretation because it proves that, despite its shallow depth, the upper part of the feature is in situ and has not been disturbed by agricultural work over twenty centuries.

\section{Neolithic ring ditch in Viecht (Bavaria, Germany)}

These neolithic rings were discovered by aerial photography at Viecht, near Landshut in Bavaria (Germany) (Braasch, 1983). A geophysical survey was then done with both magnetic and EM methods (Tabbagh et al., 1988). For the mag- a)
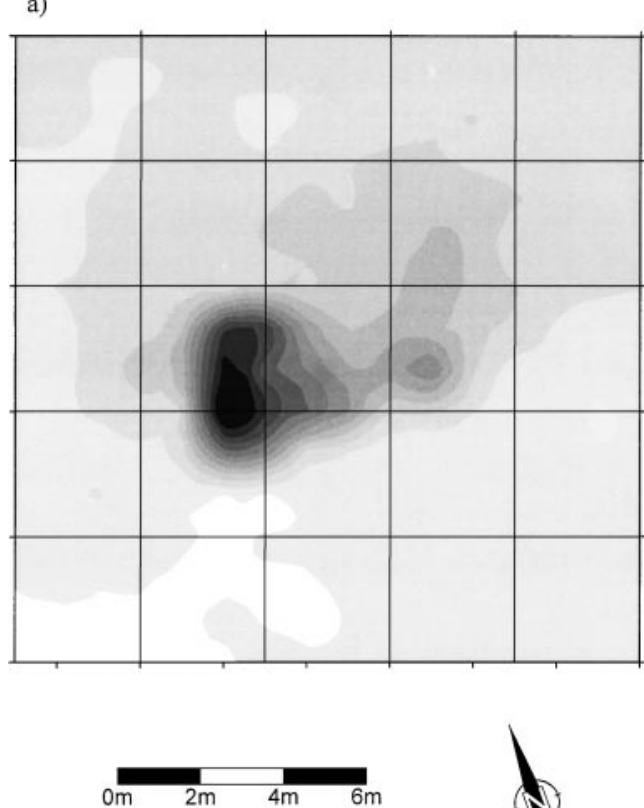

b)
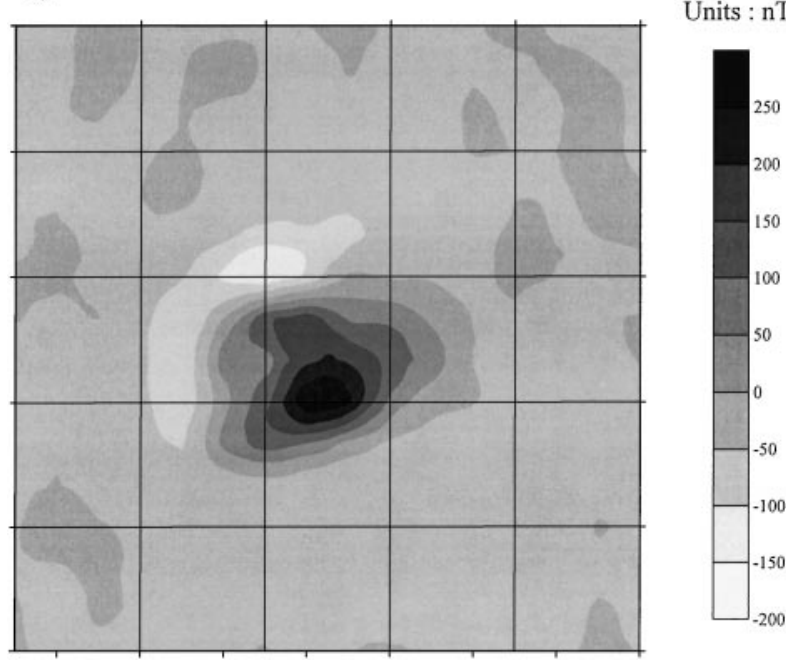

FIG. 8. Detailed map survey on the pottery workshop of Dampierre sous Bouhy (Nièvre, France): (a) SH3 survey (apparent magnetic susceptibility), (b) magnetic survey. netic survey, an optically pumped vapor magnetometer was used with measurements every $0.1 \mathrm{~s}$ (Figure 13). For the electromagnetic survey, the $\mathrm{SH} 3$ apparatus was used with a grid mesh of $1.41 \times 1.41 \mathrm{~m}^{2}$ (Figure 14). These surveys revealed ditches and pits which have been partly disturbed by plowing.

The magnetic and EM maps are similar, revealing three rings and some pits located inside these rings for the most part. The maximum of the EM anomalies is around $120 \times 10^{-5}$ SI. The
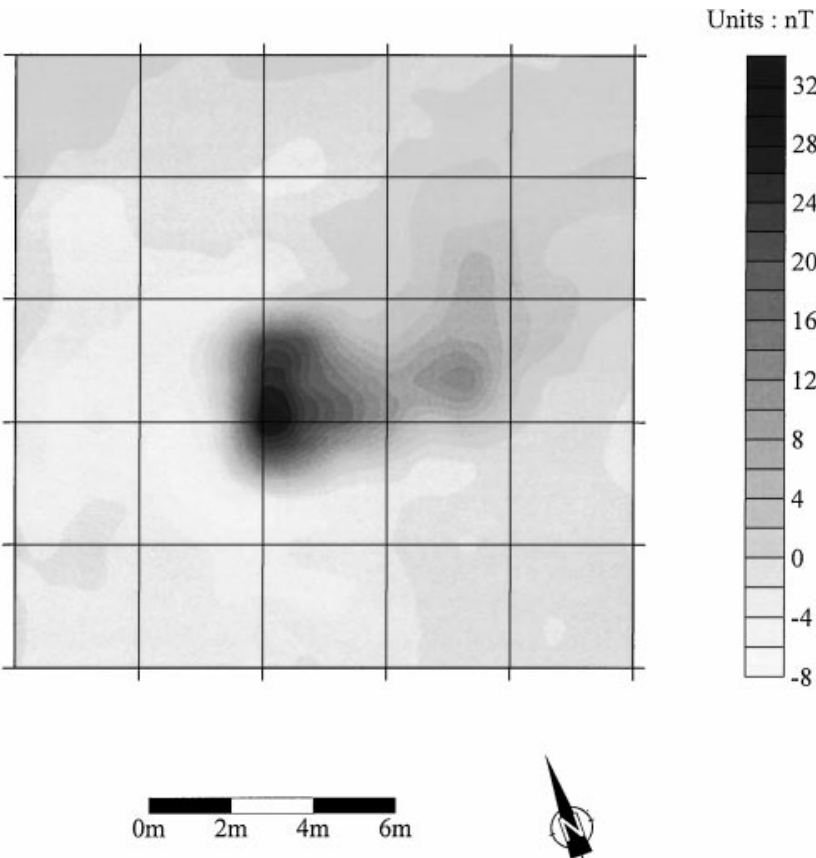

FIG. 9. SH3 filtered data from one dipole at 0.36-m depth.
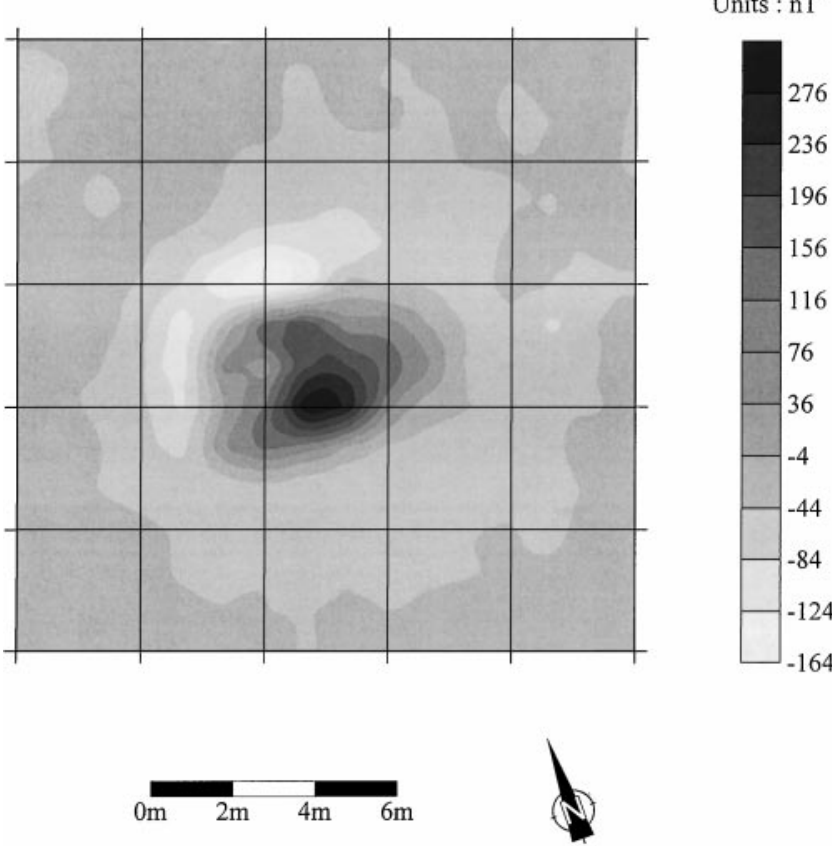

FIG. 10. Map of magnetic remanent magnetization anomaly of the kiln of Dampierre sous Bouhy. 
susceptibility measurements on soil samples collected between 0 and $0.80 \mathrm{~m}$ in depth are slightly lower than this maximum (around $80 \times 10^{-5} \mathrm{SI}$ for the pits). The top soil layer is between 0.20 and $0.40 \mathrm{~m}$ thick. The features are located between 0.40 and $0.80 \mathrm{~m}$ in depth and are thus within the depth of investigation of the $\mathrm{SH} 3$ apparatus .

The EM data were filtered with a function calculated for one dipole at $0.60-\mathrm{m}$ depth (Figure 15). The filtered data are weaker than the magnetic data by a 1.83 ratio. Again, this phenomenon can be explained by the viscous magnetization acquired during 4000 years. The $s$ value here is 0.023 and corresponds to $3.7 \%$ ratio of quadrature to in-phase susceptibility.

a)
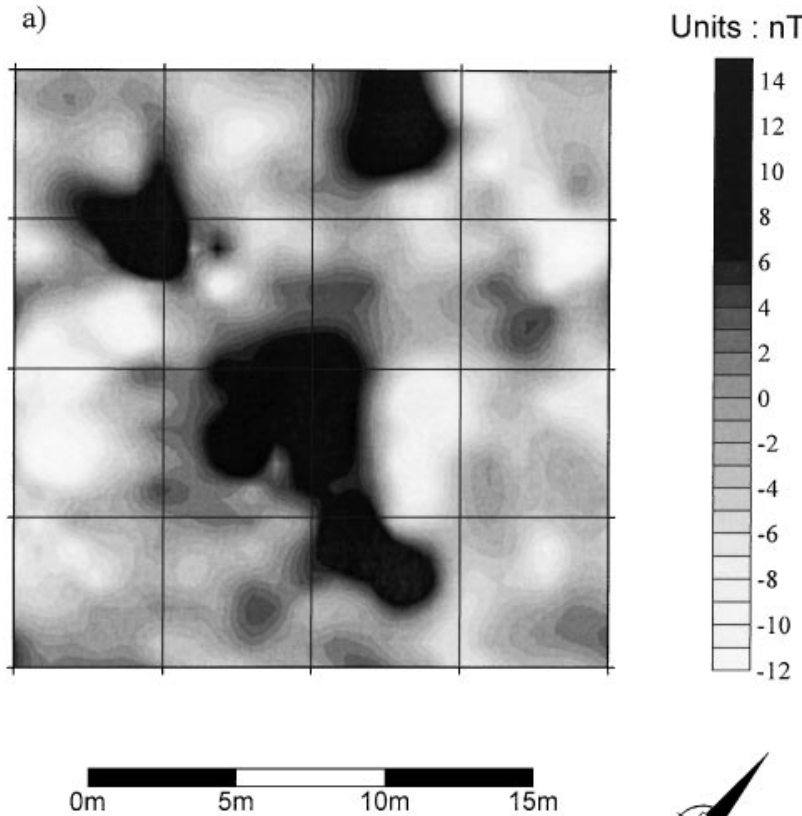

b)
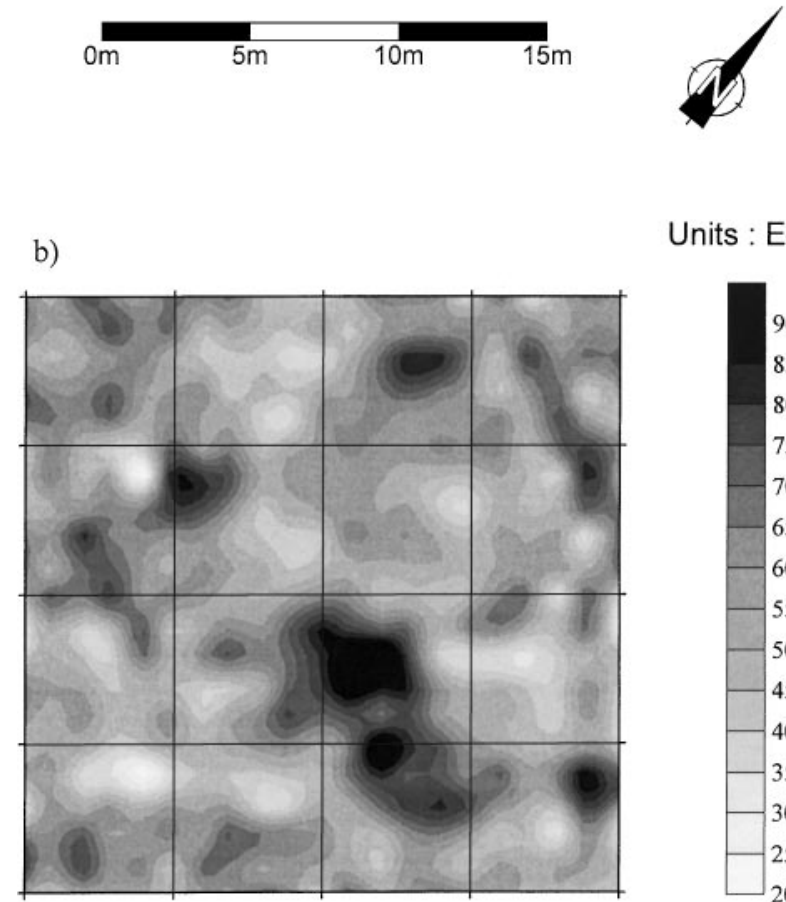

Units : E-5 SI

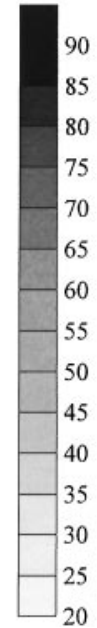

In the present case, however, the upper parts of the features have been disturbed by ploughing which destroyed the viscous magnetization. The first Euler's deconvolution is done on one of the anomalies inside the rings (Figure 13a). By using a structural index equal to 2 , we obtain a depth of $0.70 \mathrm{~m}$ for magnetic data and $1.50 \mathrm{~m}$ for EM filtered data. The result for magnetic data is in agreement with observations made using handaugered holes at the location of this anomaly (the filling of the pit extends from 0.20 to $0.80 \mathrm{~m}$ in depth). The result for EM filtered data is strongly overestimated. This phenomenon can be explained by the scattering of high-susceptibility soil in the top layer by plowing. Due to its shape, such an artificial sheetlike feature has quite a limited effect on magnetic measurements

c)
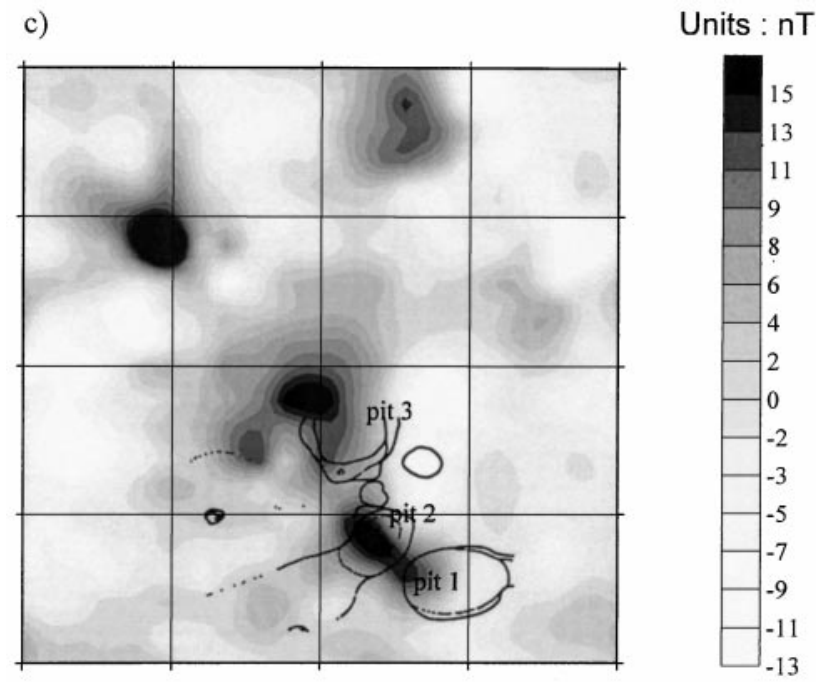

d)

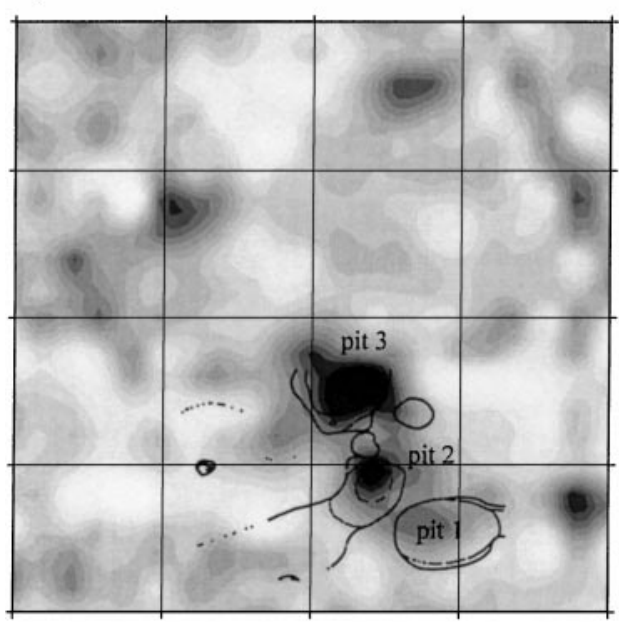

Units : E-5 SI
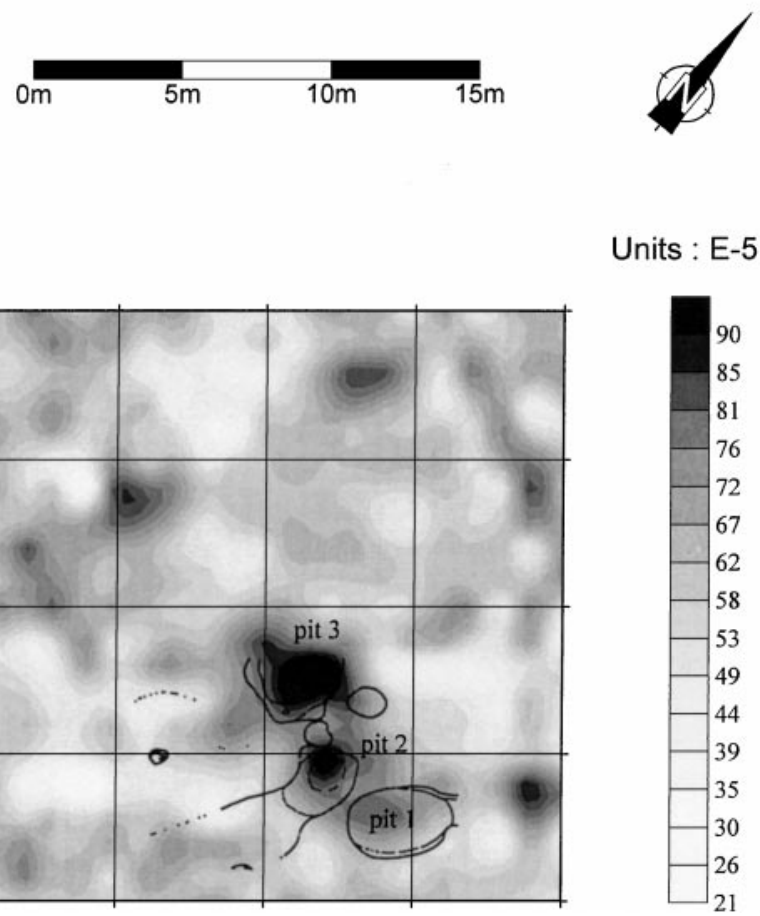

FIG. 11. Survey maps of Verdun sur le Doubs (Saône et Loire, France): (a) magnetic map with gradiometer GS858, (b) EM map with CS150 apparatus. Location of pits revealed by archeological sounding above magnetic map (c) and electromagnetic map (d). 
Table 4. Comparison between magnetic and electromagnetic filtered data for the Verdun sur le Doubs site.

\begin{tabular}{|c|c|c|c|}
\hline & $\underset{(\mathrm{nT})}{\operatorname{Minimum}}$ & $\underset{(\mathrm{nT})}{\operatorname{Maximum}}$ & $\begin{array}{l}\text { Standard } \\
\text { deviation }\end{array}$ \\
\hline Magnetic data & -13.74 & 35.89 & 5.34 \\
\hline $\begin{array}{l}\text { Filtered EM data } \\
\quad(1 \text { dipole at } 0.32 \mathrm{~m})\end{array}$ & -10.27 & 18.94 & 4.80 \\
\hline
\end{tabular}

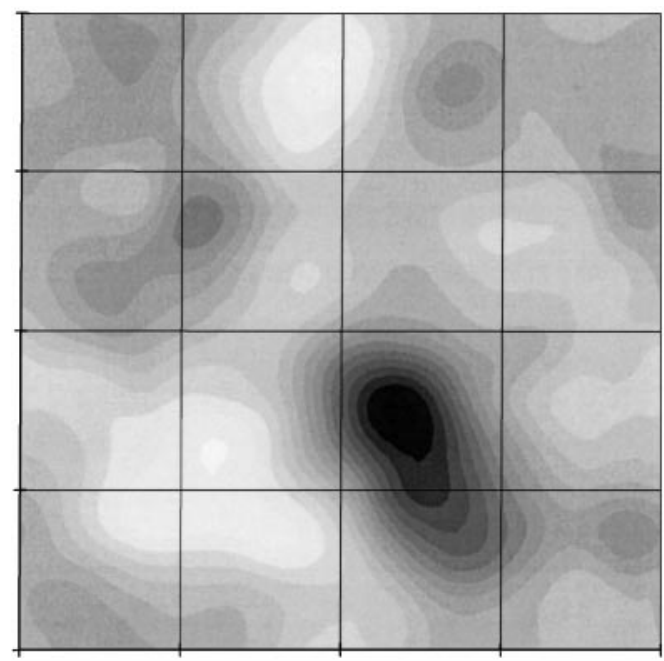

Unités : nT
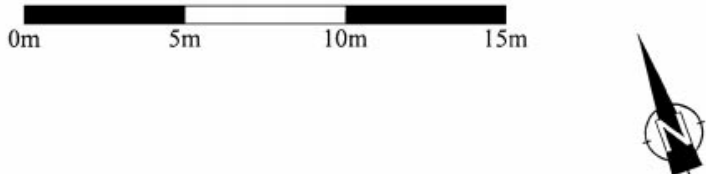

FIG. 12. Map of CS150 filtered data from one dipole at 0.32-m depth.

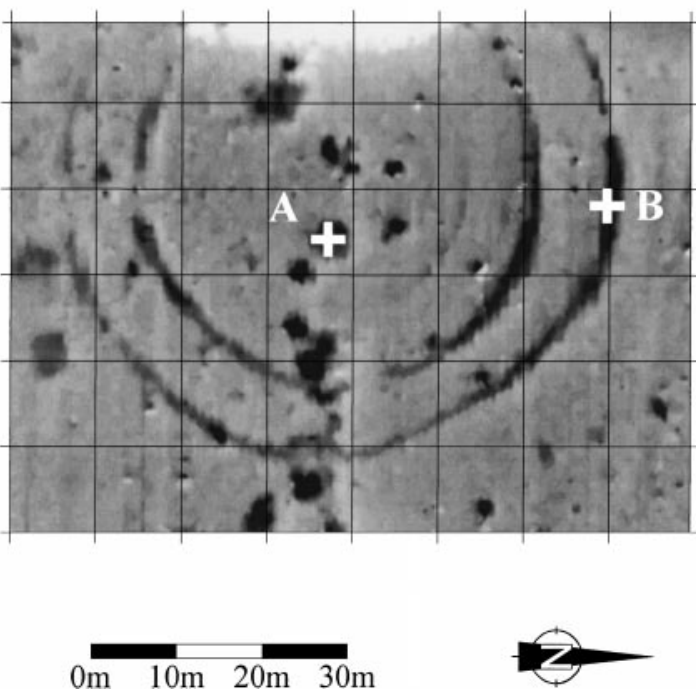

Units : nT

FIG. 13. Magnetic map of neolithic rings from Viecht (Bavaria, Germany) and location of hand-augered holes for magnetic susceptibility measurements.

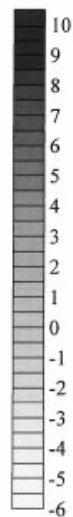

but a strong effect on EM measurements. The same phenomenon is observed for the ditch (Figure 13b), where Euler's deconvolution suggests a $0.70-\mathrm{m}$ source depth for magnetic data and a 1.55-m source depth for EM filtered data.

\section{DISCUSSION AND CONCLUSIONS}

The aim of this paper is to present the first tests of simultaneous inversion of magnetic and EM surface data by linear filtering. We must first take into account the differences between magnetic and EM measurements, particularly in terms of depth of investigation. The depth of the feature can be first estimated by Euler's deconvolution on magnetic data. If the feature is located within the depth of investigation of the EM apparatus, it may be possible to differentiate the different types of magnetization which generate the magnetic anomaly. Remanent magnetization is the easiest one to map, and the Koenigsberger's

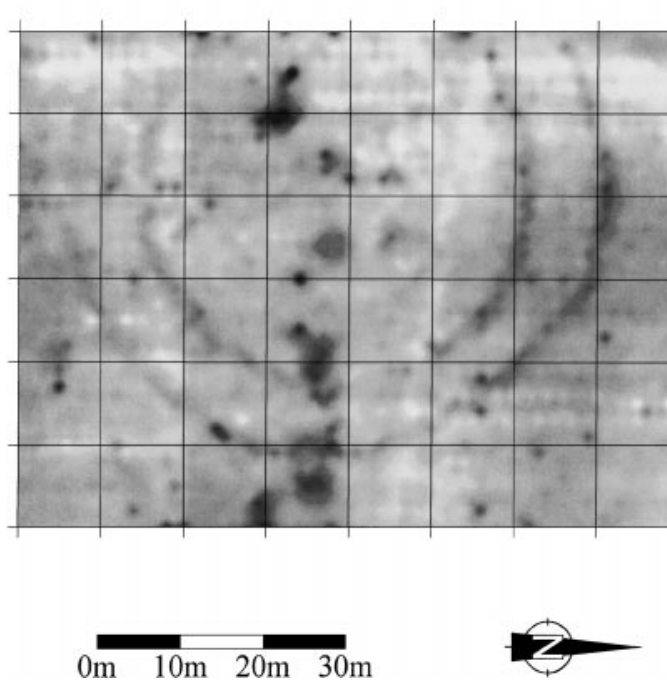

FIG. 14. EM map of neolithic rings from Viecht with SH3 apparatus.

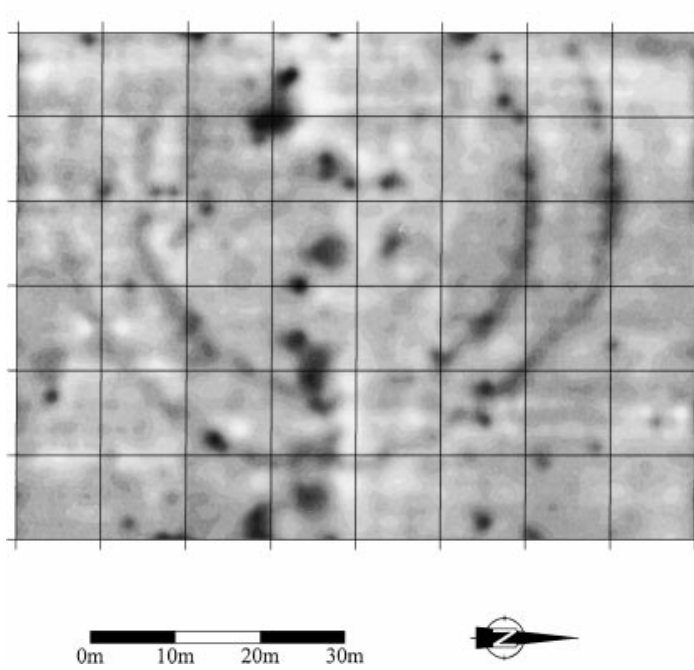

Units : nT

FIG. 15. SH3 filtered data from one dipole at $0.60 \mathrm{~m}$ depth. 
ratio can be deduced. Viscous magnetization generally has a weaker influence and will strongly depend on the age of the structure. The study of this type of magnetization will likely require more experience over archeological sites of different periods with follow-up excavations. Viscous magnetization is an important parameter to assess the age of the features and to control if the feature has been totally or partly disturbed by agricultural work. In such a case, the magnitude of the measured magnetic anomaly will be reduced, and the source depth corresponding to the magnetic anomaly deduced by filtering from the EM data will be increased.

\section{REFERENCES}

Aitken, M. J., Webster, G., and Reeds, A., 1958, Magnetic prospecting: Antiquity, 32, 270-271.

Beausillon, R., Benech, C., and Tabbagh A., 1996, A two frequency slingram apparatus for archeological and pedological applications: 2nd Mtg., Environ. Eng. Geophys. Soc., 15-18.

Benech, C., and Marmet, E., 1999, Optimum depth of investigation and conductivity response rejection of the different electromagnetic devices measuring apparent magnetic susceptibility: Archeological Prospection, 6, 31-45.

Braasch, O., 1983, Luftbildarchäologie in Süddenstchauld: Kärcher $\mathrm{GmbH}$.

Chauvin, A., Garcia, Y., Lanos, P., and Laubenheimer, F., 2000, Paleointensity of geomagnetic field recovered on archaeomagnetic sites from France: Phys. Earth Planet. Int., 120, 111-136.

Cook, J. C., and Carts, S. L., 1962, Magnetic effects and properties of typical topsoils: J. Geophys. Res., 67-2, 815-828.

Dabas, M., and Skinner, J. R., 1993, Time-domain magnetization of soils (VRM): Experimental relationship to quadrature susceptibility: Geophysics, 58, 326-333.

Desvignes, G., Barthès, V., and Tabbagh, A., 1992, Direct determination of natural remanent magnetization effect in a hole drilled in layered ground from magnetic field and susceptibility logs: Geophysics, 57, 872-884.

Desvignes, G., and Tabbagh, A., 1995, Simultaneous interpretation of magnetic and electromagnetic prospecting for magnetic feature characterisation: Archeological Prospection, 2, 129-139.
Desvignes, G., Tabbagh, A., and Benech, C., 1999, About the determination of magnetic anomaly sources: Archeological Prospection, 6 , 85-105.

Hood, P., 1965, Gradient measurements in aeromagnetic surveying: Geophysics, 30, 891-902.

Howell, B., 1968, The soil conductivity anomaly detector (SCM) in archeological prospection: Prospezioni Archeologiche, 3, 101-104.

Leborgne, E., 1955, Susceptibilité magnétique anormale du sol super ficiel: Annales de Géophysique, 6, 399-419.

Mullins, C. E., 1974, The magnetic properties of soil and their application to archaeological prospecting: Archaeo-Physika, 5, 143-348.

Pedersen, L. B., 1991, Relations between potential fields and some equivalent sources: Geophysics, 56, 961-971.

Scollar I., Tabbagh, A., Hesse, A., and Herzog, I., 1990, Archeological prospecting and remote sensing: Cambridge Univ. Press.

Tabbagh, A., 1974, Méthodes de prospection électromagnétiques applicables à la prospection archéologique: Achaeo-Physika, 5, 350437.

1984, On the comparison between magnetic and electromagnetic prospection methods for magnetic features detection: Archaeometry, 26, 171-182.

1985. The response of a three dimensional magnetic and conductive body in shallow depth E.M. prospecting: Geophys. J. Roy. Astr. Soc., 81, 215-230.

1986a, Applications and advantages of the Slingram electromagnetic method for archeological prospecting: Geophysics, 51 576-584.

Tabbagh, A., 1986b, What is the best coil orientation in the Slingram electromagnetic prospecting method?: Archaeometry, 28, 185196.

Tabbagh, A., Bossuet, G., and Becker, H., 1988, A comparison between magnetic and electromagnetic prospection of a neolithic ring ditch in Bavaria: Archaeometry, 30, 132-144.

Telford, W. M., Geldart, L. P., and Sheriff, R. E., 1990, Applied geophysics: Cambridge Univ. Press.

Thompson, D. T., 1982, EULDPH: A new technique for making computer-assisted depth estimates from magnetic data: Geophysics, 47, 31-37.

Thompson, R., and Oldfield, F., 1986, Environmental magnetism: Allen and Unwin.

Tite, M. S., and Mullins, C. E., 1969, Electromagnetic prospecting: A preliminary investigation: Prospezioni Archeologiche, 4, 95-102.

Verosub, K. L., and Roberts, A. P., 1995, Environmental magnetism: Past, present and future: J. Geophys. Res., 100-B2, 2175-2192. 